\title{
Healing effects of Wheat Grass (Triticum aestivum L) extracts on RBC Membrane Damage
}

\author{
Sudhakar Malla*, Manish Kumar Mourya, Debashree Halder, Fatemeh Gomroki, \\ Hamzah basil Mohammed
}

Indian Academy Degree College, Centre for Research \& PG studies, Bangalore, India

\author{
Email address: \\ sudhasanmoon2000@gmail.com (S. Malla)
}

\section{To cite this article:}

Sudhakar Malla, Manish Kumar Mourya, Debashree Halder, Fatemeh Gomroki, Hamzah basil Mohammed. Healing Effects of Wheat Grass (Triticum aestivum L) Extracts on RBC Membrane Damage. American Journal of Life Sciences. Special Issue: Recent Developments in Health Care through Plants and Microbes. Vol. 2, No. 6-1, 2014, pp. 22-27. doi: 10.11648/j.ajls.s.2014020601.15

\begin{abstract}
The study was mainly designed to validate the healing effects of wheat grass on RBC membrane damage. RBC membrane damage can be due to several factors, of which the free radical damage takes a major part. Many medicinal herbs have been used in study to find out their potential role in healing effects and at the same time in scavenging the free radicals. Several works were proved of the possible role of the flavonoids and phenols in the healing effects. A detailed study was done on the extracts of wheat grass in relation to its healing effects on the RBC membrane damage. The fractions (Chloroform \& Methanol) were initially screened for the Phenolics and Flavonoids and then estimated for the total polyphenols. Further, the fractions were used for tested for the invitro experiments on the rat blood sample. \% inhibition of Haemolysis, Chelating activity and SH group measurement are tested with the evaluated fractions. The plant responded positive for both the phytochemicals screened. The results of Folin -Ciocalteu total phenols photometric assay showed that the Methanol fraction was shown to contain more polyphenols (41\%), than the chloroform fraction. Both the chloroform and methanol extracts showed the inhibition of haemolysis. Percent inhibition of haemolysis was dose dependent in both the fractions. The IC50 values of chloroform and methanol are $1.689 \mathrm{mg} / \mathrm{ml}$ and $2.481 \mathrm{mg} / \mathrm{ml}$ respectively. The IC50 values were calculated from the equation of slope $(\mathrm{Y}=\mathrm{mx}+\mathrm{c})$, where $\mathrm{Y}$ is taken as 50 . The SH group content showed an abrupt decrease in the presence of the SH group inhibitor Tetrathionate. The control showed a high value normally. When the samples containing Tetrathionate were preincubated with the chloroform and methanol extracts, the values showed an abrupt increase in respect to the Tetrathionate treated samples. This increase in the values from 195 to about 326 and 389 showed the healing effects of the extracts. Methanol extract showed a high healing effect when compared to the chloroform extract. This healing effect might be due to the presence of phenolic in high content. Past studies have been done on Wheat grass in relation to their total phenolics and flavonoids. At the same phenolics were used in studying against the RBC membrane damage. Our study suggests that the wheat grass can be used as a better and novel therapeutic agent in healing the RBC membrane damage induced by free radicals.
\end{abstract}

Keywords: Triticum aestivum, Total Phenolics, \% Inhibition Hemolysis, Chelating Activity, SH Groups

\section{Introduction}

The RBC membrane damage is induced by the generation of free radicals. Therefore anemia and other blood related disorders to a large extent can be treated by the use of free radical scavengers potentially found in some medicinal plants. Many of the studies done so far suggests that free radical-induced oxidative damages lead to several pathological events including coronary heart disease and cancer [1]. In particular, lipid peroxidation in biological membranes has attracted much attention in relation to the destruction of membrane structure and impairment of enzymatic functions [2]. The oxidation of RBC membranes serves as a model for the oxidative damage of biomembranes [3, 4]. The oxidation of erythrocyte and its ghost's membranes induced by free radicals have been studied and also found that free radicals produced in the aqueous phase attack the membrane to induce oxidation of 
lipids and eventually cause hemolysis $[5,6]$.

Many of the works done suggests of the possibility that antioxidants reduce the risk of degenerative diseases by inhibiting free radical induced oxidative damage [7]. So, many of the scientists have examined both natural and synthetic antioxidants for the inhibition of lipid peroxidation on membrane systems [8]. The fragility of the membranes are caused due to the oxidative damage of the thiol groups which is associated with the low glutathione(GSH) levels in the RBC cells[9]. The RBC membrane damage can be caused due to haemoglobin denaturation and also due to extreme anemic conditions $[10,11]$.

Mostly Flavonoids are found to provide stability to the RBC membrane. Flavonoids are the naturally occurring compounds of the poly Phenolic groups, found especially in the plants [12]. The flavonoids possess the anti inflammatory, antioxidant, anti allergic and hepato-protective properties. According to the concentration as well as the redox potential present depends on the flavonoid antioxidants as well as pro oxidants $[13,14]$. Flavonoids are also proved of the potential health effects through multiple mechanisms. Apart from the main role in transporting oxygen and carbon dioxide, erythrocytes play also an important role in organism antioxidative defense [15].

Many herbs have been used for treating several Blood disorders since ages. In the ayurveda several of the formulations have been in use to treat this membrane damage. Many of such extracts or formulations have not yet been studied at the scientific level. For the first time, we propose to study the healing effects of the wheat grass on the RBC membrane damage. Wheatgrass is a kind of grass [16]. The above-ground parts, roots, and rhizome are used to make medicine. Wheatgrass is primarily used as a concentrated source of nutrients. It contains vitamin $\mathrm{A}$, vitamin $\mathrm{C}$, and vitamin $\mathrm{E}$, iron, calcium, magnesium, and amino acids. Wheatgrass is used to treat many conditions, but so far there isn't enough scientific evidence to support effectiveness for any of these uses [17]. Wheatgrass is used for increasing production of haemoglobin, the chemical in red blood cells that carries oxygen; improving blood sugar disorders, such as diabetes; preventing tooth decay; improving wound healing; and preventing bacterial infections[18]. It is also used for removing deposits of drugs, heavy metals, and cancercausing agents from the body; and for removing toxins from the liver and blood [19].

Keeping in view of the role of phenolics in healing the $\mathrm{RBC}$ membrane damage, we tried to investigate the role of wheat grass in healing effects on RBC membrane damage. The plant is cultivated and extracted with both polar solvents like methanol and non polar solvents like chloroform followed by the Phytochemical screening for Flavonoids and Phenols. The healing effects were studied on the rat blood samples invitro. The extracts were studied for the \% inhibition of Haemolysis, Chelating activity and $\mathrm{SH}$ group measurement.

\section{Materials \& Methods}

\subsection{Wheat Grass Cultivation and Extraction}

Adequate quantity of unpolished wheat grain was soaked overnight in water in a container. The soaked wheat-grain were spread on the surface of the soil filled in plastic trays. Climatic conditions were maintained to help in sprouting. The plantlets after 9days, which grew to a height of about $15-16 \mathrm{~cm}$ were selected for the extraction procedure.

The wheat grass blades were cut and homogenized in a Mortar \& pestle and about $10 \mathrm{gm}$ of the homogenized paste was dissolved in $20 \mathrm{ml}$ of (Methanol and Chloroform). The samples were then incubated in an orbital shaker for overnight. The solvents were then filtered and supernatants containing the components are concentrated in a hot air oven at $55^{\circ} \mathrm{C}$. The concentrated samples are then dissolved in $10 \%$ DMSO. The crude samples are later stored at $4^{0} \mathrm{C}$ for further use. The two fractions (Methanol and Chloroform) were used for further screening experiments.

\subsection{Screening for Phytochemicals}

The two fractions were then screened for the phytochemicals especially, the Flavonoids and Phenols.

\subsection{Flavonoid Test}

The extracts were screened for flavonoids by the protocol described elsewhere [20]. Briefly to $0.2 \mathrm{ml}$ of each extract, $1 \mathrm{ml}$ of ammonia solution was added and mixed properly. To this mixture $1 \mathrm{ml}$ of concentrated Sulphuric acid was added. Development of Yellow colour was indicated as a positive for flavonoids.

\subsection{Phenolics Test}

The extracts were screened for phenolic by the protocol described elsewhere [21]. Briefly to $0.2 \mathrm{ml}$ of extract, 1 to 2 drops of ferric chloride (0.5\%) was added. Development of Green colour indicates positive for phenolics.

\subsection{Analysis of Phenolic Content}

The extracts collected were then analyzed for the total phenol content. The Phenolic content was assayed using the Folin-Ciocalteu assay [23]. Phenolic compounds, at basic $\mathrm{pH}$ reduce the phosphomolybdic and phosphotungstic acid reagent, forming a blue complex. In brief, $0.5 \mathrm{ml}$ of extract was mixed with $0.5 \mathrm{ml}$ of Folin-Ciocalteu reagent and incubated for $5 \mathrm{~min}$ at room temperature. This was followed by the addition of $0.5 \mathrm{ml}$ sodium carbonate (15\%). The mixture was incubated in the dark at room temperature for about 2 hours. After the blue colour was developed, absorbance was taken at $765 \mathrm{~nm}$. Gallic acid was used as standard. The concentration of Phenolic content was expressed as milligram Gallic acid equivalents per gram of dried weight (mg GAE/g dried weight). All the experiments were carried in triplicates. 


\subsection{Invitro Experiments on Rat Blood Sample}

Blood samples were collected from healthy winstar rats (ether anaesthetized) in heparinized tubes, and the RBC content was isolated by centrifugation $(3000 \mathrm{rpm}$ for 10 min) and, subsequently, washed three times with $0.9 \%$ saline. The tubes were then centrifuged at $12,000 \mathrm{~g}$ for 10 min to obtain packed cells [5]. The suspension was later used to prepare a $10 \% \mathrm{v} / \mathrm{v}$ erythrocyte suspension with phosphate buffer $(\mathrm{pH}=7.4)$.

\subsection{Haemolysis}

Haemolysis is normally indicated by the sudden appearance of a clear red solution in place of the previously murky and turbid suspension of red blood cells. This is due to the swelling and bursting of the red blood cells at the penetration of solute and water through the membrane takes place. 10\% hematocrit (PCV) was used. The extracts with different concentrations were used for screening the haemolysis values along with the control. The treated and untreated samples were checked for the absorbance values after incubation. Two tubes labelled control and test were used for the study.

In the control tube, to $50 \mu 1 \mathrm{RBC}$ cells $0.2 \mathrm{ml} \mathrm{PBS}$ was added and incubated for $37^{\circ} \mathrm{C}$ for 3 hours. To the suspension 20volumes of distilled water (about $1.8 \mathrm{ml}$ ) was added and centrifuged at $8000 \mathrm{rpm}$ for 10 minutes. Absorbance of the suspension was measured at 540nm

$50 \mu 1$ of RBC suspensions were preincubated with extracts (Methanol \& Chloroform). The same procedure was done for the test sample but pretreated with both the extracts (chloroform and methanol). Absorbance was measured at $540 \mathrm{~nm}$. The percent inhibition of haemolysis was calculated using the formula \% haemolysis = Absorbance of test sample /Absorbance of control x 100.

\subsection{Chelating Activity}

Iron is released from the haemoglobin and the release is accompanied by the Met haemoglobin formation [23]. Transition metal ions such as $\mathrm{Fe}^{2+}$, are able to move free electrons and this way they allow the formation and propagation of many radical reactions, even if they start with relatively non reactive radicals. Ferrozine can form complexes with $\mathrm{Fe} 2+$, originating a violet colour.

The chelating of ferrous ions by extracts was estimated by method described elsewhere [24]. Briefly, $50 \mu 1$ of $2 \mathrm{mM}$ $\mathrm{FeCl}_{2}$ was added to $1 \mathrm{ml}$ of different concentrations of the extract $(0.2,0.4,0.8,1.6$ and $3.2 \mathrm{mg} / \mathrm{ml})$. The reaction was initiated by the addition of $0.2 \mathrm{ml}$ of $5 \mathrm{mM}$ ferrozine solution. The mixture was vigorously shaken and left to stand at room temperature for $10 \mathrm{~min}$. The absorbance of the solution was thereafter measured at $562 \mathrm{~nm}$.

The percentage inhibition of ferrozine- $\mathrm{Fe}^{2+}$ complex formation was calculated as $\left[\left(\mathrm{A}_{0}-\mathrm{A}_{\mathrm{s}}\right) / \mathrm{A}_{\mathrm{s}}\right] \times 100$, where $\mathrm{A}_{0}$ was the absorbance of the control, and $A_{s}$ was the absorbance of the extract/ standard. $\mathrm{Na}_{2}$ EDTA was used as positive control.

\subsection{SH Group Measurement}

The SH groups were measured to determine the effect of the extracts on RBC damage. Briefly, the procedure is as follows. Extracts (methanol \& chloroform) were added to the membrane suspension and Centrifuged at 3,000rpm for 10 minutes. The suspensions later were washed with PBS and added with tetrathionate (inhibitor of $\mathrm{SH}$ groups). The contents are then incubated for 30 minutes at $37^{\circ} \mathrm{C} .10 \%$ SDS were added to the membrane and then 5, 5 dithio-bis (2nitrobenzoic acid) were added. Absorbance of the contents was measured at $512 \mathrm{~nm}$ after incubation for an hour at $37^{0} \mathrm{C}$.

\section{Results and Discussion}

\subsection{Phytochemical Screening}

The result of the preliminary phytochemical screening gives a clear evidence for the presence of Phenolic and flavonoids which are very essential towards the healing of the RBC membranes.

Table 1. Results of Phytochemical screening for the different plants extracts. -ve (Absent), + (Low in abundance), ++ (Moderate in abundance), +++ (High in abundance).

\begin{tabular}{llll}
\hline S. No & Flavonoid test & Chloroform & Methanol \\
\hline 1 & Flavonoids & ++ & - \\
2 & Phenolics & - & +++ \\
\hline
\end{tabular}

\subsection{Estimation of Polyphenols}

The absorbance of the blue colour that developed was read at $765 \mathrm{~nm}$ using a spectrophotometer. The concentration of total Phenolic content was expressed as Gallic acid equivalents by reference to the Gallic acid standard calibration curve. The calibration equation for Gallic acid was $\mathrm{y}=1.0703 \mathrm{x}-0.002\left(\mathrm{R}^{2}=0.9906\right)$, where $\mathrm{x}$ is the Gallic acid concentration in $\mathrm{mg} / \mathrm{L}$ and $\mathrm{y}$ is the absorbance reading at $765 \mathrm{~nm}$. The concentration of total Phenolic compounds in the extract was determined by using the formula: $\mathrm{T}=\mathrm{CV} / \mathrm{M}$; Where, $\mathrm{T}=$ Total Phenolic content $\mathrm{mg} / \mathrm{gm}$ of plant extract in $\mathrm{GAE}, \mathrm{C}=$ Concentration of Gallic acid from the calibration curve, $\mathrm{V}=$ volume of the extract in $\mathrm{ml}, \mathrm{M}=\mathrm{wt}$ of the pure plant methanol extract.

The results of Folin -Ciocalteu total phenols photometric assay are reported in table 1 and figure 1 . Methanol fraction was shown to contain more polyphenols $(41 \%)$, than the chloroform fraction.

Table 2. Table showing the flavonoid and total polyphenolic content values. The concentration of the polyphenols and flavonoids in respect to their standards are expressed in $\mu \mathrm{g} / \mathrm{ml}$. All the values are average of triplicates.

\begin{tabular}{llll}
\hline \multirow{3}{*}{ Extract } & \multicolumn{3}{l}{ Wheat Grass } \\
\cline { 2 - 4 } & Polyphenols & & Flavonoids \\
\cline { 2 - 4 } & Concentration & \% Phenols & Concentration \\
\hline Chloroform & $0.3022 \pm 0.09$ & 12 & $40.029 \pm 0.13$ \\
Methanol & $1.019 \pm 0.09$ & 41 & $19.333 \pm 0.05$ \\
\hline
\end{tabular}




\subsection{RBC Haemolysis}

The different extracts were used for screening the haemolysis values along with the control. The treated and untreated samples were checked for the absorbance values after incubation. The absorbance was measured at $540 \mathrm{~nm}$. The percent inhibition was calculated in terms of the control (PBS).

Both the chloroform and methanol extracts showed the inhibition of haemolysis. Percent inhibition of haemolysis was dose dependent in both the fractions. The percent inhibition might be due to the presence of excess amount of flavonoids and phenolic.

Table 3. Table showing the values of \% inhibition of haemolysis on incubation with the extracts. The concentration of the crude extract was measured in $\mu \mathrm{g} / \mathrm{ml}$.

\begin{tabular}{lll}
\hline Extract & Conc $(\boldsymbol{\mu g} / \mathbf{m l})$ & \% inhibition \\
\hline \multirow{2}{*}{ Chloroform } & 20 & 24.56 \\
& 10 & 21.49 \\
\multirow{2}{*}{ Methanol } & 20 & 53.29 \\
& 10 & 34.21 \\
\hline
\end{tabular}

\subsection{Chelating Activity}

The wheat grass extracts quenches the formation of ferrozine $-\mathrm{Fe} 2+$ complex. The protective effects of wheat grass towards the erythrocyte membranes can be attributed to their iron chelating capacities, since they can extract iron ions and hinder radical reactions. Moreover, the phenolic and flavonoid compounds can scavenge free hydroxyl and peroxy radicals and protect the membranes. The phenolic compounds stabilize the erythrocyte membrane by interaction with the membrane phospholipids.

Table 4. Table showing the values of \% inhibition of haemolysis due to the extracts. The concentrations of the fractions were expressed in $\mathrm{mg} / \mathrm{ml}$. All the values are average of triplicates.

\begin{tabular}{lll}
\hline \multirow{2}{*}{ Conc (mg/ml) } & Extracts (Wheat Grass) \\
\cline { 2 - 3 } & Chloroform (\% activity) & Methanol (\% activity) \\
\hline 0.2 & 6.00 & 9.00 \\
0.4 & 11.00 & 15.00 \\
0.8 & 15.00 & 25.00 \\
1.6 & 32.00 & 51.00 \\
3.2 & 66.58 & 92.00 \\
\hline
\end{tabular}

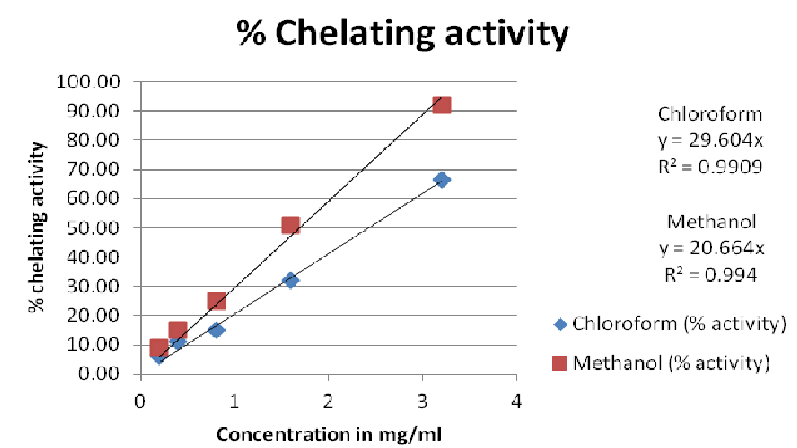

Fig 1. Graph showing the percent chelating activity in the presence of ferrozine. The concentrations of the chloroform and methanol extracts were expressed in $\mathrm{mg} / \mathrm{ml}$. All the values are average of triplicates.
The IC50 values of chloroform and methanol are $1.689 \mathrm{mg} / \mathrm{ml}$ and $2.481 \mathrm{mg} / \mathrm{ml}$ respectively. The IC50 values were calculated from the equation of slope $(\mathrm{Y}=\mathrm{mx}+\mathrm{c})$, where $\mathrm{Y}$ is taken as 50 .

\subsection{SH Group Measurement}

Absorbance was measured at $412 \mathrm{~nm}$ after incubation for 1 hour at $37^{\circ} \mathrm{C}$ in the presence of reduced glutathione. To measure the $-\mathrm{SH}$ group content per milligram of protein, protein concentrations were determined using the Lowry method. The calibration equation for Reduced glutathione standard was $y=0.0025 x-0.002\left(R^{2}=0.9965\right)$, where $x$ is the reduced glutathione concentration in $\mathrm{mg} / \mathrm{L}$ and $\mathrm{y}$ is the absorbance reading at $412 \mathrm{~nm}$.

Table 5. Table showing the values of the SH groups in terms of the protein content present in the sample. The SH groups were expressed in $\mu \mathrm{M} / \mathrm{mg}$ of protein. All the values are average of triplicates.

\begin{tabular}{ll}
\hline Extracts (Wheat Grass) & \\
\hline Concentration $(\mathbf{m g} / \mathbf{m l})$ & SH groups $(\boldsymbol{\mu M} / \mathbf{m g})$ protein \\
\hline Control (without Tetrathionate) & 412.00 \\
Tetrathionate & 195.00 \\
Tetrathionate and Chloroform extract & 326.00 \\
Tetrathionate and Methanol extract & 389.00 \\
\hline
\end{tabular}

The SH group content showed an abrupt decrease in the presence of the $\mathrm{SH}$ group inhibitor Tetrathionate. The control showed a high value normally. When the samples containing Tetrathionate were preincubated with the chloroform and methanol extracts, the values showed an abrupt increase in respect to the Tetrathionate treated samples. This increase in the values from 195 to about 326 and 389 showed the healing effects of the extracts. Methanol extract showed a high healing effect when compared to the chloroform extract. This healing effect might be due to the presence of phenolic in high content.

\section{Discussion}

In the present study, the blood sample collected from the healthy winstar rats. The blood collected from the rats was then evaluated invitro with the extracts treated with the plant extract and observed for the parameters [3, 5]. The parameters are checked for the effectiveness of the drug.

Both the chloroform and methanol extracts showed the inhibition of haemolysis. Percent inhibition of haemolysis was dose dependent in both the fractions. The percent inhibition might be due to the presence of excess amount of flavonoids and phenolic. The IC50 values of chloroform and methanol are $1.689 \mathrm{mg} / \mathrm{ml}$ and $2.481 \mathrm{mg} / \mathrm{ml}$ respectively. The IC50 values were calculated from the equation of slope $(\mathrm{Y}=\mathrm{mx}+\mathrm{c})$, where $\mathrm{Y}$ is taken as 50 . In addition to causing lipid per oxidation, per oxidants can cause the oxidation of -SH groups in proteins and $\mathrm{RBC}$ membranes. The $-\mathrm{SH}$ groups are highly reactive and can be a target during oxidative stress.

Glutathione directly protects membrane proteins and preserves their stability. Decreased levels of glutathione 
lead to a decrease in - $\mathrm{SH}$ groups and can result in the oxidization of membrane -SH groups and loss of membrane stability [25].

The $\mathrm{SH}$ group content was used as a marker for the RBc damage analysis $[3,5]$. SH group showed an abrupt decrease in the presence of the SH group inhibitor Tetrathionate. The control showed a high value normally. When the samples containing Tetrathionate were preincubated with the chloroform and methanol extracts, the values showed an abrupt increase in respect to the Tetrathionate treated samples. This increase in the values from 195 to about 326 and 389 showed the healing effects of the extracts. Methanol extract showed a high healing effect when compared to the chloroform extract. This healing effect might be due to the presence of phenolic in high content.

\section{Conclusion}

In the ayurveda several of the formulations have been in use to treat RBC membrane damage. Many of such extracts or formulations need to be validated at the scientific level. For the first time, we propose to study the healing effects of the wheat grass on the RBC membrane damage. The RBC membrane damage can be caused due to haemoglobin denaturation and also due to extreme anaemic conditions. And the studies so far done proved of the vital role of Flavonoids and Phenolics in healing the RBC membrane damage. Our studies done on the wheat grass showed abundant quantity of Phenolics and flavonoids. Even the study done on the blood samples invitro also proved of the role of wheat grass in inhibiting the hemolysis, and chelating activity. Further we plan to concentrate the morphology studies using the microscopy studies.

\section{References}

[1] B Halliwell. 1996. Oxidative stress, nutrition and health Experimental strategies for optimization of nutritional antioxidant intake in humans. Free Radical Res; 25: 57-74.

[2] T F Slater, K H Cheeseman, D Armstrong, R S Sohal, R G Cutler. 1984. Free radicals, lipid peroxidation and cancer. New York: Raven Press,;pp. 293-305.

[3] H Einsele, MR Clemens, H Remmer. 1985 Effect of ascorbate on red blood cell lipid peroxidation. Free Radical Res Commun, 1: 63-7.

[4] MCM Vissers, A Stern, F Kuypers, J V D Berg, CC Winterbourn. 1994Membrane changes associated with lysis of red blood cells by hypochlorous acid. Free Radical Biol Med, 16: 703-12.

[5] T Koga, K Moro, J Terao. 1998. Protective effect of a vitamin $\mathrm{E}$ analog, phosphatidylchromanol, against oxidative hemolysis of human erythrocytes. Lipids; 33: 589-95.

[6] E Niki, E Komur, M Takahashi, S Urano, E Ito, K Terao.1988. Oxidative hemolysis of erythrocytes and its inhibition by free radical scavengers. $J$ Biol Chem; 263: 19809-14.
[7] F Testa, J Nuti, Hayek, et al., 2012. "Di-(2-ethylhexyl) phthalate and autism spectrum disorders," The American Society For Neurochemistry, vol. 4, no. 4, pp. 223-229.

[8] DE Discher, P Carl. 2001-2006. Cell Bio let New insights into red cell network structure, elasticity, and spectrin unfolding a new fold review, A J Physiol, 593-606.

[9] J. Baio. 2012. "Prevalence of Autism spectrum disorders: autism and developmental disabilities monitoring network, 14 Sites, United States, 2008," Morbidity and Mortality Weekly Report, vol. 61, no. 3, pp. 1-19.

[10] P. Favero, M. Leonart, A. Nascimento. 2013. Electroforese de proteínas de membrane eritrocitária no diagnóstico de doença haemolítica por defeito de membrana. Revista Brasileira de Análises Clínica 35, 45-47.

[11] G Wagner, D Chiu, M Yee, B Lubin. 1986. Red cell vesiculation - a common membrane physiological event. Journal of Laboratory and Clinical Medicine 108, 315-324.

[12] A Arora, TM Byrem, MG Nair, GM Strasburg. 2000. Modulation of liposomal membrane fluidity by flavonoids and isoflavonoids. Arch Biochem Biophys 373:102-109.

[13] B. Bukowska, J. Michałowicz, A. Krokosz, P. Sicińska, 2007. Comparison of the effect of phenol and its derivatives on protein and free radical formation in human erythrocytes (in vitro). Blood Cell Mol. Dis. 39, 238.

[14] M.Y. cimen. 2008. "free redical metabolism in human erythrocytes," Clin. Chim. Acta, vol .30, no-1-2.

[15] M. Ferrali, C. Signorini, Caciotti, B., Sugherini, L., Ciccoli, L., Giachetti, D., Comporti, M. 1997. Protection against oxidative damage of erythrocyte membrane by the flavonoid quercetin and its relation to iron chelating activity. FEBS Letters 416, 123-129.

[16] G. Bar-Sela, et al. 2007. "Wheat grass juice may improve hematological toxicity related to chemotherapy in breast cancer patients: a pilot study," Nutrition and Cancer, 58(1): 43-8.

[17] K G Harding, H L Morris, G K Patel. 2002. Science, medicine and the future: healing chronic wounds. BMJ 324: 160-163.

[18] H L Jacob, I Burhan, A Scarpellini, A Thomas, A Imberty, R Romain, T Johnson, A Gutierrez, And E A. M. Verderio 2012. Identification of a heparin binding site that regulates cell adhesion to fibronectin transglutaminase-2 matrix; J Biol Chem. May 25, 287(22): 18005-18017.

[19] S D Kulkarni, J C Tilak, R Acharya, N S Rajurkar, TPA Devasagayam, AVR Reddy. 2006. Evaluation of the antioxidant activity of wheatgrass (Triticum aestivum L.) as a function of growth under different conditions. Phytother Res; 20: 218-27.

[20] AAL Ordonez, JD Gomez, MA Vattuone, MI Isla. 2006. Antioxidant activities of Sechium edule (Jacq). Food Chem; 97:452-458.

[21] BE Omoruyi, G Bradley, AJ Afolayan. 2012. Antioxidant and phytochemical properties of Carpobrotus edulis (L.) bolus leaf used for the management of common infections in HIV/AIDS patients in Eastern Cape Province. Complementary and Alternative Medicine; 12(215):2-9. 
[22] V. L. Singleton and J A. Rossi. 1965. Colorimetry of Total Phenolics with Phosphomolybdic-Phosphotungstic Acid ReagentsAm. J. Enol. Vitic. 16:144-158.

[23] M Ferrali, C Signorini, B. Caciotti, L. Sugherini, L. Ciccoli, D Giachetti. and M. Comporti. 1997. Protection against oxidative damage of erythrocyte membrane by the flavonoid quercetin and its relation to iron chelating activity. FEBS Lett 416, 123-129.
[24] TCP Dinis, VMC Madeira, MLM Almeida. 1994. Action of phenolic derivates (acetoaminophen, salycilate and 5aminosalycilate) as inhibitors of membrane lipid peroxidation and as peroxyl radical scavengers. Arch. Biochem. Biophys. 315: 161-169.

[25] G Poli. 1993. Free Radicals: From Basic Science to Medicine. Basel: Birkhauser. pp. 47-65.pp. 365-73.pp. 389-98. 